\title{
Cardiovascular Imaging Applications in Clinical Management of Patients Treated with Cardiac Resynchronization Therapy
}

\author{
Cinzia Valzania ${ }^{1, *}$, Fredrik Gadler ${ }^{2,3}$, Eva Maret ${ }^{4,5}$ and Maria J. Eriksson ${ }^{4,5}$ \\ 1 Department of Cardiology, IRCCS—Azienda Ospedaliero-Universitaria di Bologna, Policlinico di S.Orsola, \\ 40138 Bologna, Italy \\ 2 Department of Cardiology, Karolinska University Hospital, 17177 Stockholm, Sweden; fredrik.gadler@sll.se \\ 3 Department of Medicine, Karolinska Institutet, 17177 Stockholm, Sweden \\ 4 Department of Clinical Physiology, Karolinska University Hospital, 17177 Stockholm, Sweden; \\ eva.maret@ki.se (E.M.); maria.j.eriksson@sll.se (M.J.E.) \\ 5 Department of Molecular Medicine and Surgery, Karolinska Institutet, 17177 Stockholm, Sweden \\ * Correspondence: cinzia.valzania@gmail.com; Tel.: +39-051-344859; Fax: +39-051-349858
}

Received: 16 November 2020; Accepted: 16 December 2020; Published: 19 December 2020

\begin{abstract}
Cardiovascular imaging techniques, including echocardiography, nuclear cardiology, multi-slice computed tomography, and cardiac magnetic resonance, have wide applications in cardiac resynchronization therapy (CRT). Our aim was to provide an update of cardiovascular imaging applications before, during, and after implantation of a CRT device. Before CRT implantation, cardiovascular imaging techniques may integrate current clinical and electrocardiographic selection criteria in the identification of patients who may most likely benefit from CRT. Assessment of myocardial viability by ultrasound, nuclear cardiology, or cardiac magnetic resonance may guide optimal left ventricular (LV) lead positioning and help to predict LV function improvement by CRT. During implantation, echocardiographic techniques may guide in the identification of the best site of LV pacing. After CRT implantation, cardiovascular imaging plays an important role in the assessment of CRT response, which can be defined according to LV reverse remodeling, function and dyssynchrony indices. Furthermore, imaging techniques may be used for CRT programming optimization during follow-up, especially in patients who turn out to be non-responders. However, in the clinical settings, the use of proposed functional indices for different imaging techniques is still debated, due to their suboptimal feasibility and reproducibility. Moreover, identifying CRT responders before implantation and turning non-responders into responders at follow-up remain challenging issues.
\end{abstract}

Keywords: cardiac resynchronization therapy; cardiovascular imaging; echocardiography; nuclear cardiology; cardiac magnetic resonance

\section{Introduction}

Cardiac resynchronization therapy (CRT) is an established additive treatment for heart failure patients with severe left ventricular (LV) systolic dysfunction and prolonged QRS duration [1-4]. Heart failure patients with dilated cardiomyopathy and ventricular conduction delay display an asynchronous LV electro-mechanical activation pattern [5]. CRT can restore a more homogenous contraction pattern by decreasing intraventricular dyssynchrony, thus improving LV systolic function and volumes, a condition referred to as LV reverse remodelling [6]. Several randomized trials have reported CRT-induced improvements in clinical endpoints (symptoms, exercise capacity, quality of life) and echocardiographic variables (systolic function, LV size, mitral regurgitation) [7]. Moreover, 
a reduction in all-cause mortality and hospitalization rate has been shown in heart failure patients treated with CRT [2-4].

Current guidelines support the use of CRT in symptomatic patients with heart failure, left ventricular ejection fraction (LVEF) $\leq 35 \%$, and wide QRS complex ( $\geq 130 \mathrm{~ms}$ ) [1]. To date, the role of LV dyssynchrony in patient selection has not yet been validated. Despite CRT clinical and prognostic beneficial effects [2-4], 20 to $30 \%$ of patients do not respond to CRT, and the reasons are currently not completely known [5]. Inappropriate patient selection or LV lead positioning, as well as suboptimal device programming, have been considered responsible for the lack of response to CRT. Much interest has been focused on how to identify potential responders to CRT before implantation, or to make non-responders turn into responders during follow-up.

Considering these open issues, cardiovascular imaging techniques, including echocardiography, nuclear cardiology, cardiac magnetic resonance (CMR), and multi-slice computed tomography (CT), may offer broad applications in heart failure patients undergoing CRT. Most studies have focused on issues before or after CRT implantation. Our aim was to provide an overview of current cardiovascular imaging applications before, during, and after implantation of a CRT device. In our opinion, the contribution of this comprehensive update on cardiovascular imaging is, therefore, to take into account different phases of the clinical management of CRT patients.

\section{Cardiovascular Imaging before CRT Implantation}

\subsection{Assessment of LV Function and Dyssynchrony}

In the past few years, much interest has focused on the implementation of cardiovascular imaging techniques in patient selection for CRT. Table 1 summarizes the main applications, advantages and disadvantages of different cardiovascular imaging modalities which can be used before CRT implantation. Echocardiography has been the most widely used imaging modality to evaluate LV systolic function and mechanical dyssynchrony before CRT implantation. LVEF is calculated by assessing LV volumes from the apical four- and two-chamber views, according to Simpson's equation. Various echocardiographic methods, including M-mode echocardiography and tissue velocity imaging (Figure 1), and different echocardiographic indexes have been investigated to assess mechanical dyssynchrony [5]. Although the initial studies on LV intraventricular dyssynchrony, assessed by echocardiography, have given promising results in predicting CRT response [5], the PROSPECT trial has raised concerns regarding the widespread use of echo methodologies before implantation, by showing a low feasibility and high inter-laboratory variability of echo dyssynchrony variables [8]. More recently, several two-dimensional (2D) strain imaging and three-dimensional (3D) echocardiographic variables have been proposed to assess LV mechanical dyssynchrony [9-12]. In particular, global longitudinal strain [9] and the time difference between peak radial strain of the anteroseptal and posterolateral segments [10] have been suggested as predictors of CRT-induced reverse remodelling. Similarly, systolic dyssynchrony indexing using 3D echocardiography seems to be independently associated with long-term prognosis after CRT [11]. In the PREDICT-CRT trial [13], the echocardiographic assessment of apical rocking and septal flash was associated with better survival after CRT. Apical rocking has been described as a short septal motion of the apex early in systole, followed by a long motion to the lateral side, deriving from a late lateral wall activation in patients with left bundle branch block $[12,13]$. Septal flash has been described as an early posterior movement of the interventricular septum towards the LV, caused by an early contraction of the right ventricular (RV) free wall in patients with left bundle branch block [12,13]. In the PREDICT-CRT trial, both apical rocking and septal flash were visually assessed, and their identification was associated with favourable long-term prognosis in patients undergoing CRT [13]. More recently, systolic septal myocardial stretching by speckle tracking echocardiography was shown to be a predictor of CRT response with an additive predictive value over apical rocking [14]. Despite these encouraging results, the prognostic role of echocardiographic dyssynchrony indexes is still debated. In a recent study, radial strain-guided LV 
lead positioning, combined with multimodality imaging, did not provide a significant improvement in CRT response and clinical outcome measures [15]. Moreover, although several echo dyssynchrony indexes have been studied, up to now none have been validated for CRT patient selection beyond current guidelines [1]. Therefore, at present it is not recommended that CRT should be withheld from patients who meet the standard selection criteria because of negative results of an echocardiographic dyssynchrony evaluation [16].

Table 1. Advantages and disadvantages of different imaging modalities.

\begin{tabular}{|c|c|c|c|c|}
\hline Imaging Modality & Parameter & Technique & Advantages & Disadvantages \\
\hline \multirow{3}{*}{ Echocardiography } & $\begin{array}{l}\text { LV volumes and } \\
\text { systolic function }\end{array}$ & $\begin{array}{l}\text { 2D echocardiography } \\
\text { 3D echocardiography }\end{array}$ & \multirow{3}{*}{$\begin{array}{l}\text { Wide availability; } \\
\text { no radiation exposure; low costs } \\
\text { Used in pre- and post-procedure, } \\
\text { and follow-up evaluation }\end{array}$} & \multirow{3}{*}{$\begin{array}{l}\text { High operator dependence; } \\
\text { high interobserver and } \\
\text { interlaboratory variability; } \\
\text { dyssynchrony evaluation } \\
\text { not standardized }\end{array}$} \\
\hline & LV dyssynchrony & $\begin{array}{l}\text { M-mode echocardiography } \\
\text { Tissue Doppler Imaging } \\
\text { Tissue Velocity Imaging } \\
\text { Strain Imaging } \\
\text { 3D echocardiography }\end{array}$ & & \\
\hline & $\begin{array}{c}\text { Myocardial } \\
\text { contractile reserve }\end{array}$ & $\begin{array}{l}\text { Pharmacological or exercise } \\
\text { stress echocardiography }\end{array}$ & & \\
\hline \multirow{3}{*}{ Nuclear cardiology } & $\begin{array}{l}\text { LV volumes and } \\
\text { systolic function }\end{array}$ & $\begin{array}{l}\text { SPECT myocardial imaging } \\
\text { Radionuclide angiography }\end{array}$ & \multirow{3}{*}{$\begin{array}{l}\text { High reproducibility of LVEF by } \\
\text { radionuclide angiography; } \\
\text { low operator dependence } \\
\text { Mainly in pre-procedure } \\
\text { evaluation }\end{array}$} & \multirow{3}{*}{$\begin{array}{l}\text { Relatively low availability; } \\
\text { radiation exposure; } \\
\text { high costs; phase analysis } \\
\text { not clinically validated }\end{array}$} \\
\hline & LV dyssynchrony & $\begin{array}{l}\text { Phase analysis of SPECT, } \\
\text { radionuclide angiography, } \\
\text { PET }\end{array}$ & & \\
\hline & $\begin{array}{l}\text { Myocardial } \\
\text { viability and } \\
\text { scar burden }\end{array}$ & $\begin{array}{c}\text { SPECT myocardial imaging } \\
\text { Radionuclide angiography } \\
\text { PET }\end{array}$ & & \\
\hline \multirow{4}{*}{$\begin{array}{l}\text { Cardiac magnetic } \\
\text { resonance imaging }\end{array}$} & $\begin{array}{l}\mathrm{LV} \text { volumes and } \\
\text { systolic function }\end{array}$ & & \multirow{4}{*}{$\begin{array}{l}\text { High accuracy and reproducibility; } \\
\text { low operator dependence; } \\
\text { visualisation of myocardial scar, } \\
\text { focal and diffuse fibrosis, } \\
\text { tissue characterization } \\
\text { Mainly in pre-procedure } \\
\text { evaluation }\end{array}$} & \multirow{4}{*}{$\begin{array}{c}\text { Relatively low availability; } \\
\text { high costs; } \\
\text { low frame rate; } \\
\text { dyssynchrony evaluation } \\
\text { not standardized }\end{array}$} \\
\hline & LV dyssynchrony & $\begin{array}{c}\text { Steady-state free } \\
\text { precession imaging } \\
\text { Myocardial tagging } \\
\text { Phase contrast tissue } \\
\text { velocity mapping } \\
\text { Displacement encoding with } \\
\text { stimulated echoes } \\
\text { Feature-tracking imaging }\end{array}$ & & \\
\hline & $\begin{array}{l}\text { Myocardial } \\
\text { viability and } \\
\text { scar burden }\end{array}$ & & & \\
\hline & $\begin{array}{l}\text { Cardiac venous } \\
\text { anatomy }\end{array}$ & & & \\
\hline \multirow{2}{*}{ Cardiac CT } & $\begin{array}{l}\mathrm{LV} \text { volumes and } \\
\text { systolic function }\end{array}$ & & \multirow{2}{*}{$\begin{array}{l}\text { High accuracy and reproducibility; } \\
\text { low operator dependence } \\
\text { Mainly in pre-procedure } \\
\text { evaluation }\end{array}$} & \multirow{2}{*}{$\begin{array}{l}\text { Relatively low availability; } \\
\text { radiation exposure; } \\
\text { high costs }\end{array}$} \\
\hline & $\begin{array}{l}\text { Cardiac venous } \\
\text { anatomy }\end{array}$ & & & \\
\hline
\end{tabular}

2D: two-dimensional; 3D: three-dimensional; CT: computed tomography; LV: left ventricular; LVEF: left ventricular ejection fraction; PET: positron emission tomography; SPECT: single-photon emission computed tomography.

Before CRT implantation, cardiac function and dyssynchrony can also be assessed by nuclear cardiology techniques, including single photon emission computed tomography (SPECT) myocardial imaging and equilibrium radionuclide angiography with Fourier phase analysis [17]. SPECT myocardial perfusion imaging with phase analysis may be used for a simultaneous evaluation of LV perfusion, systolic function, and dyssynchrony [17]. Equilibrium radionuclide angiography provides a highly reproducible assessment of LVEF [17]. In equilibrium radionuclide angiography with Fourier phase analysis, LVEF is computed on the basis of relative end-diastolic and end-systolic counts derived from the time-activity curve (Figure 2). Phase images are generated from the scintigraphic data and a phase angle is assigned to each pixel of the phase image by using a specific computer program (Figure 2). Interventricular dyssynchrony is calculated as the absolute difference between LV and RV mean phase angles, and intraventricular dyssynchrony is expressed by the standard deviation of LV and RV phase histograms, respectively $[18,19]$. In heart failure patients undergoing CRT, the standard deviation of LV phase angle was shown to be a predictor of response to CRT [20]. However, the role of phase analysis parameters in clinical decision-making should be validated by further prospective studies. Recently, phase analysis of gated positron emission tomography has been proposed for the 
evaluation of mechanical ventricular synchrony, but the technique requires further research and clinical investigation [21].

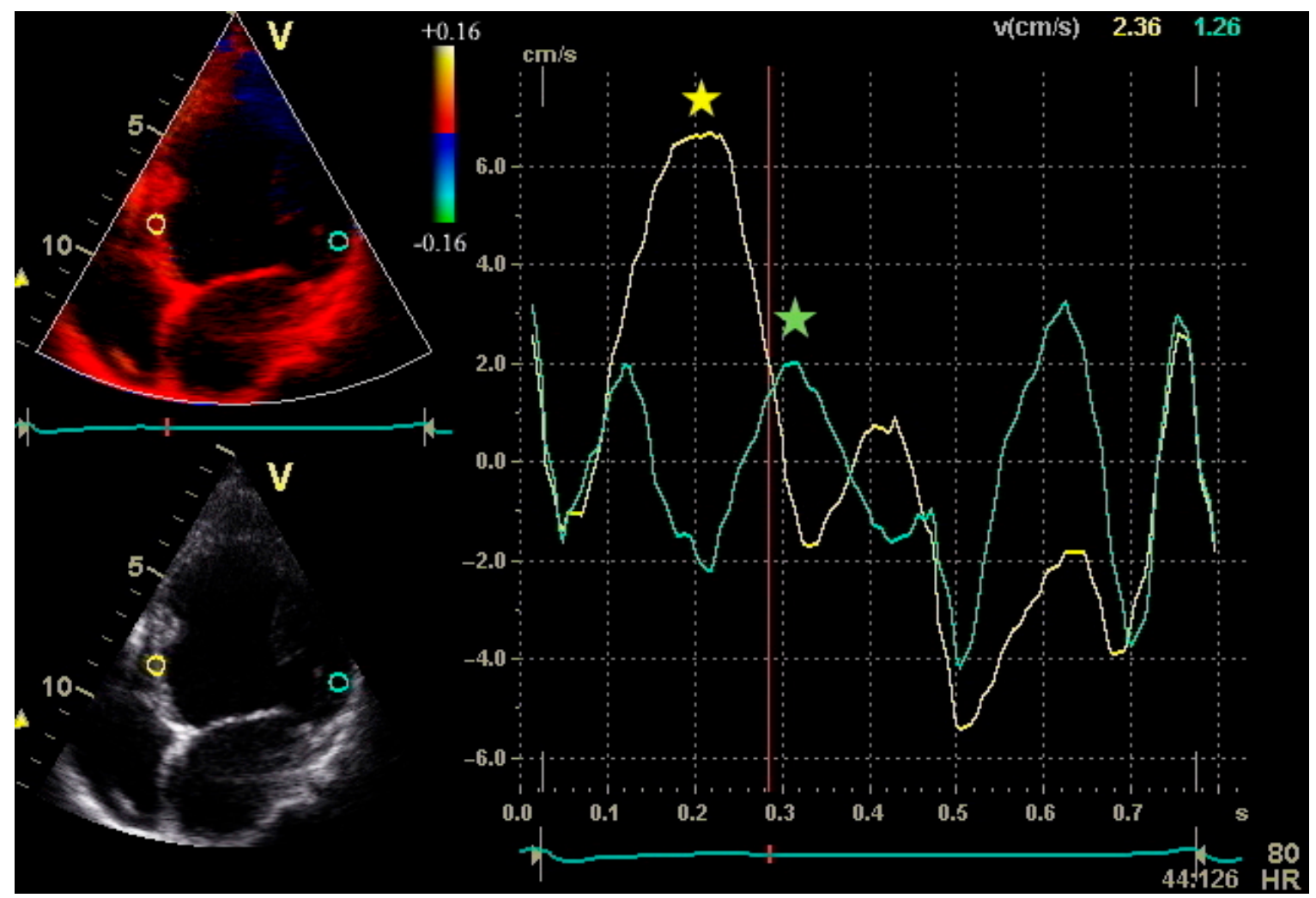

Figure 1. Peak systolic velocities of the septum and lateral wall by Tissue Velocity Imaging from the apical four-chamber view in a patient with non-ischaemic dilated cardiomyopathy. Sample volumes are placed in the basal portions of the septum and lateral wall. The septal-to-lateral delay is an index of intraventricular dyssynchrony and can be calculated as the difference between time to peak velocity of the septum and lateral wall.

CMR imaging has emerged as an alternative option for LV function and dyssynchrony assessment in CRT candidates. CMR provides accurate and reproducible information on LV systolic function and myocardial contraction pattern [12]. Several CMR techniques, such as conventional steady-state free precession imaging, myocardial tagging, phase contrast tissue velocity mapping, displacement encoding with stimulated echoes, and feature-tracking imaging, can be applied to derive LV dyssynchrony parameters [12]. Previous studies have shown an association between CMR dyssynchrony parameters, CRT response, and clinical events at follow-up [22,23]. In a recent study, CMR assessment of myocardial work and septal viability was found to be a predictor of CRT response with higher accuracy than QRS morphology, QRS duration, and echocardiographic parameters like septal flash, apical rocking, and systolic stretch index [24]. 


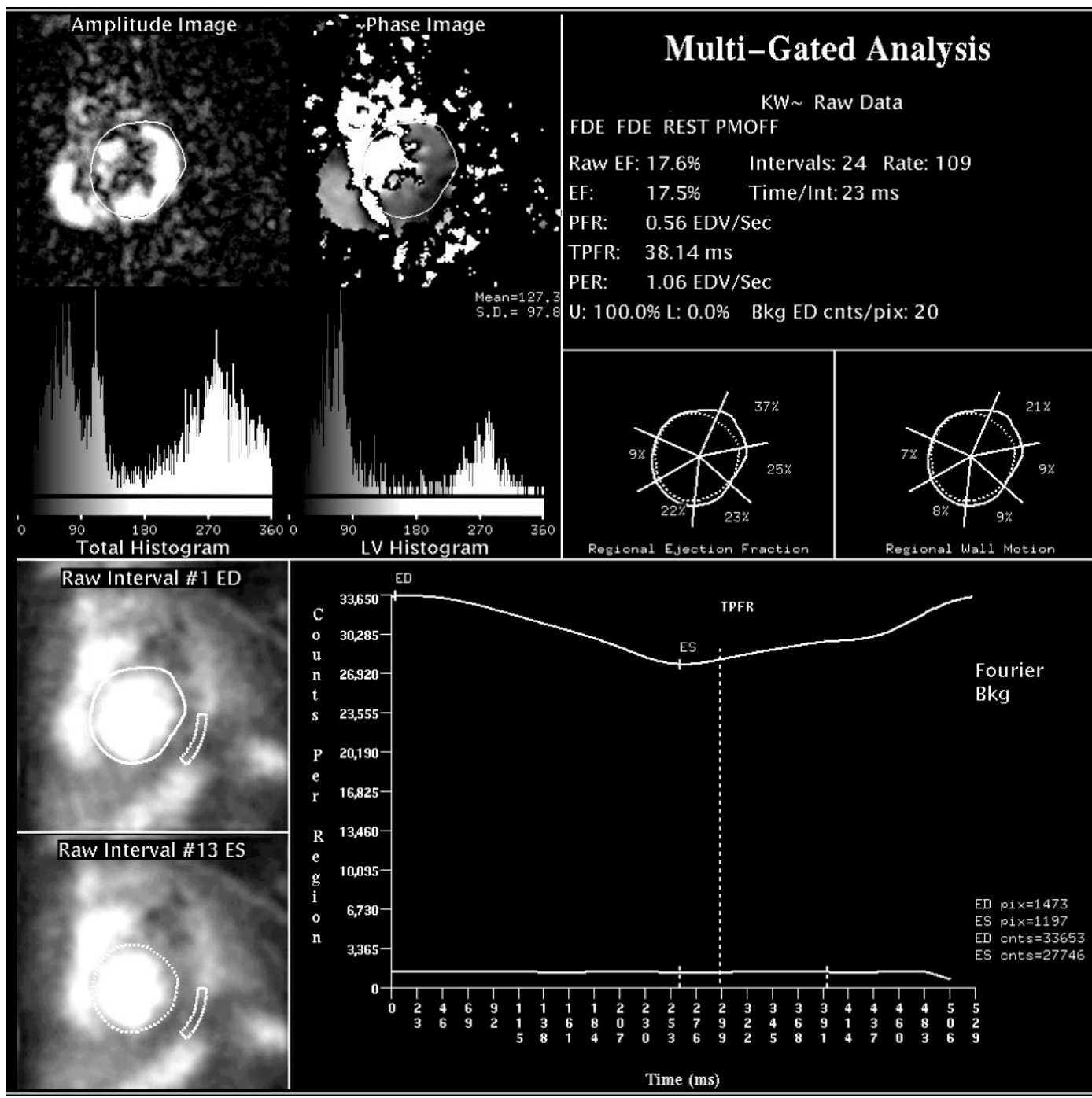

Figure 2. Radionuclide angiographic determination of LV systolic function and dyssynchrony parameters in a patient with non-ischaemic dilated cardiomyopathy. Upper part: LV amplitude and phase histograms for mechanical dyssynchrony assessment. Lower part: background-corrected, time-activity curve, obtained by a semi-automated edge-detection method. LVEF can be computed on the basis of relative end-diastolic and end-systolic counts.

\subsection{Assessment of Myocardial Contractile Reserve and Scar Burden}

Previous studies have investigated the potential role of myocardial contractile reserve in the identification of patients who may most likely respond to CRT $[25,26]$. LV myocardial contractile reserve can be assessed by pharmacological or exercise stress echocardiography in heart failure patients undergoing CRT. The presence of myocardial contractile reserve before CRT implantation, as assessed by dobutamine stress echocardiography, has been recognized as a predictor of CRT response [25]. In a systematic review and meta-analysis of 11 studies on either dobutamine or stress echocardiography in CRT patients, the presence of LV myocardial contractile reserve, identified as reduction in wall motion score index and/or increase in LVEF, was associated with higher response to CRT according to clinical and echocardiographic criteria [26]. 
Pre-implant LV myocardial viability and scar burden can also be assessed by nuclear cardiology techniques or CMR. In a study based on 201Tl SPECT myocardial perfusion imaging, global scar burden and scar density near the LV lead tip were associated with an unfavourable response to CRT in ischaemic heart failure patients [27]. Consistently, scar or reversible ischemia, as assessed by SPECT myocardial perfusion imaging, in or close to LV pacing site were found to be independent predictors of heart failure hospitalization and death in CRT recipients with ischaemic cardiomyopathy [28]. Lehner et al. [29] assessed myocardial viability and dyssynchrony before CRT implantation by using ECG-gated Fluor-18-fluorodeoxyglucose $\left({ }^{18} \mathrm{~F}-\mathrm{FDG}\right)$ positron emission tomography. The authors found a significantly higher number of viable and dyssynchronous myocardium in CRT responders, defined by clinical improvement in combination with LVEF increase of $>5 \%$ [29].

CMR with late gadolinium enhancement can provide information on the entity and localization of scarred myocardium with high accuracy [12]. Figures 3 and 4 show examples of CMR with late gadolinium enhancement imaging for scar identification in myocardial infarction. Leyva et al. [30] investigated the use of late gadolinium CMR before CRT implantation, showing that pacing LV scarred myocardium was associated with high risk of cardiovascular death, hospitalizations for heart failure, and death from any causes. Conversely, in the study by Taylor et al. [31], LV lead positioning over non-scarred LV segments, as assessed by late gadolinium enhancement CMR, was associated with better LV reverse remodelling and clinical outcomes at follow-up.
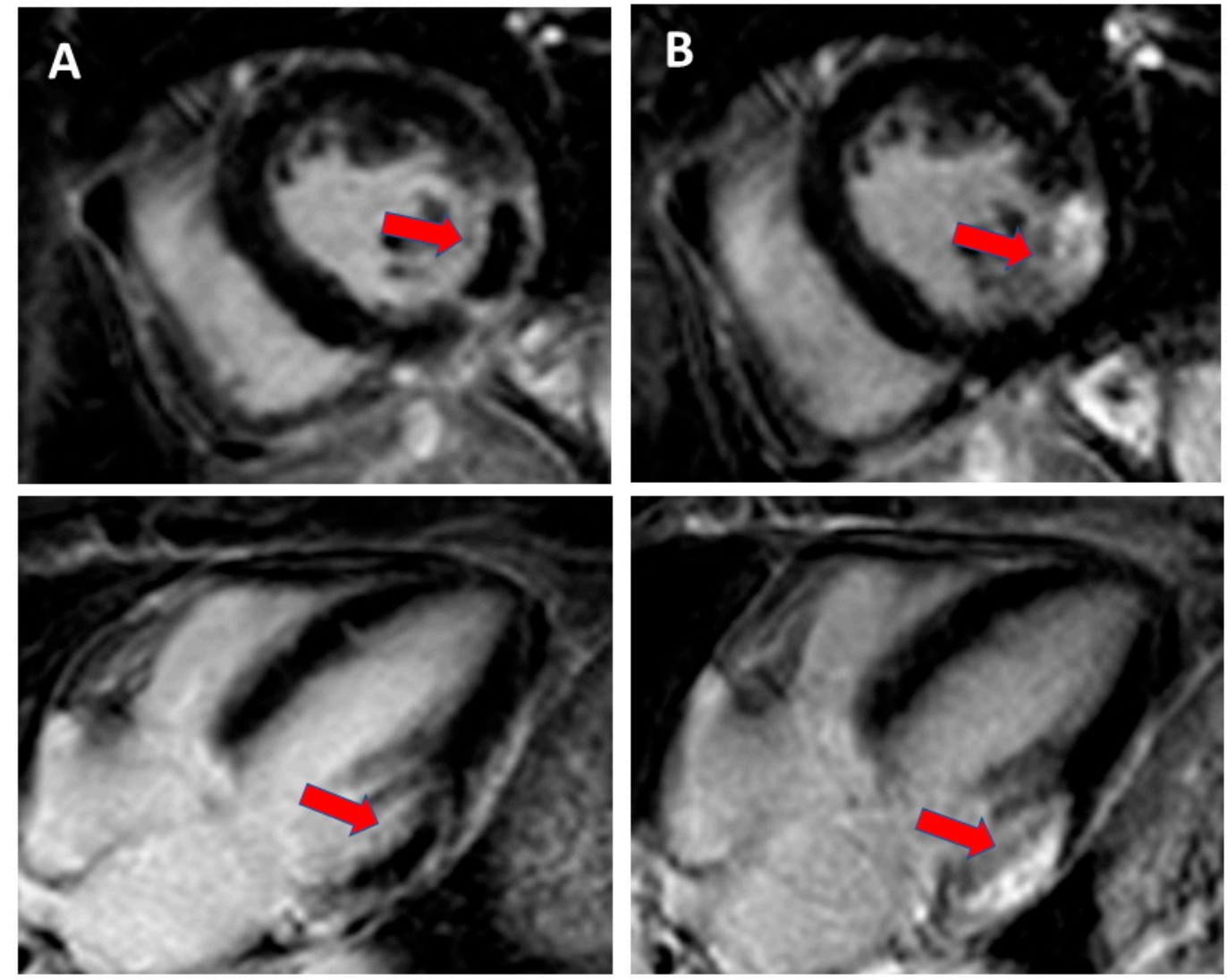

Figure 3. Cardiac magnetic resonance with late gadolinium enhancement (LGE) imaging for scar identification in myocardial infarction (MI): (A). day 1 after MI with no-reflow area (red arrow) and (B). day 14 after MI with scarring (red arrow). 

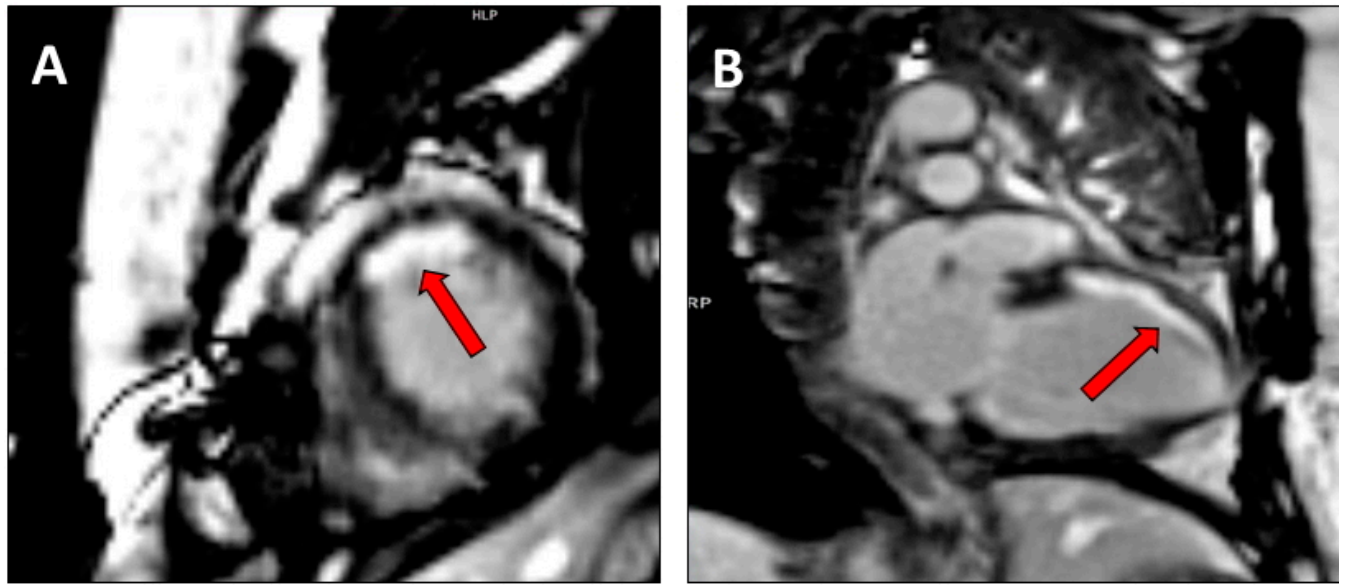

Figure 4. Cardiac magnetic resonance with LGE imaging in a mid/apical subendocardial myocardial infarction (red arrow) in (A). short axis mid ventricular view and (B). two chamber view.

\subsection{Assessment of Cardiac Venous Anatomy}

Before CRT implantation, it may be useful to have detailed information on cardiac venous anatomy to guide LV lead positioning. The anatomic characteristics of the coronary sinus system may indeed hamper the access to coronary sinus tributary veins. Multi-slice CT can be used to assess cardiac venous anatomy (Figure 5), as well as LV volumes and LVEF [32]. In the study by Girsky et al. [33], a pre-procedural review of coronary venous anatomy, assessed by cardiovascular CT, was associated with decreased implantation times and the utilization of contrast, fluoroscopy, and guide catheters.

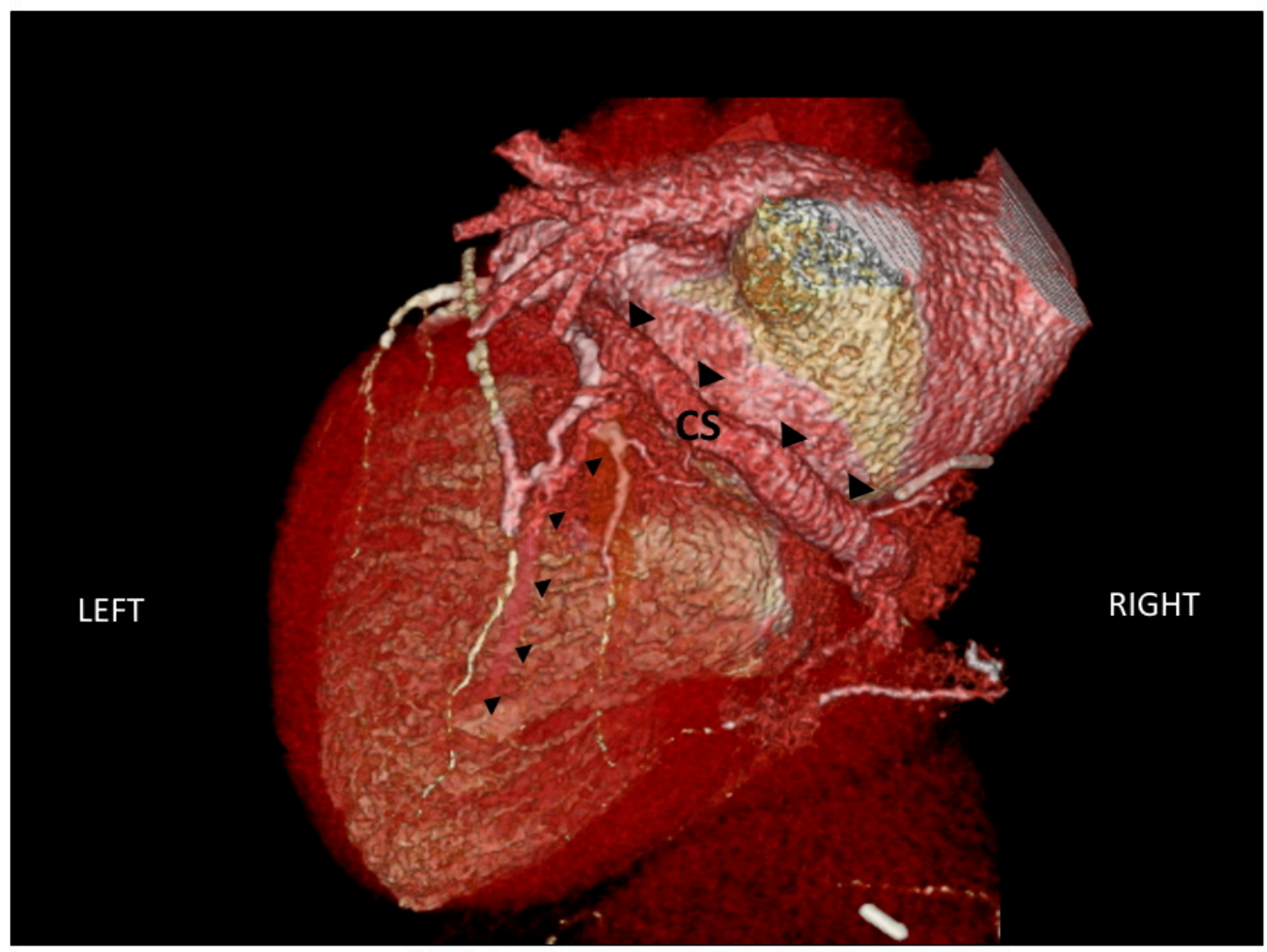

Figure 5. CT scan of the anatomic characteristics of the coronary sinus (indicated by large black triangles) and one of the tributary veins (indicated by small black triangles). CS: coronary sinus. 
In a recent pilot study [34], a combined imaging approach, based on the assessment of coronary venous anatomy, in contrast to $\mathrm{CT}$ venography and myocardial viability by myocardial perfusion imaging, showed promising results for the identification of the optimal LV pacing site. Despite these results, anatomic constraints may often require using less favourable coronary venous sites during CRT implantation, and this may be responsible for a portion of non-responders observed in clinical practice.

\section{Cardiovascular Imaging during CRT Implantation}

Intraoperative transthoracic or intracardiac echocardiographic imaging to guide lead positioning during CRT implantation is not an established clinical practice. In literature, few studies have been published on the feasibility of cardiovascular imaging at the time of CRT implantation. In the study by Bai et al. [35], intracardiac echocardiography with velocity vector imaging was performed during CRT implantation to assess LV dyssynchrony and guide LV lead positioning. The approach was feasible and safe, and echo-guided intraprocedural resynchronization was found to be a predictor of CRT response at a 6-month follow-up [35]. Intraoperative transthoracic echo assessment of left pre-ejection interval was used to guide RV lead placement during CRT implantation, and it was found to improve LV synchrony [36]. Sperzel et al. [37] conducted a feasibility study on intraoperative interventricular mechanical dyssynchrony assessment using an electroanatomic mapping system. Echocardiographic M-mode evaluation of septal-to-posterior wall motion delay was used as a reference. Interventricular mechanical dyssynchrony evaluation was found to be feasible during CRT implantation [37]. More recently, in the study by Salden et al. [38], optimal LV pacing sites were identified preprocedurally by using CMR and contrast $\mathrm{CT}$ venography, and during implantation, cardiac imaging data were overlaid onto live fluoroscopy for a real-time-image-guided LV lead positioning. At present, the applicability in clinical practice and the outcome benefits of these intraoperative techniques require further investigations.

\section{Cardiovascular Imaging after CRT Implantation}

\subsection{Assessment of LV Remodelling}

Cardiovascular imaging is essential to assess CRT response in terms of reverse LV remodelling. Various imaging techniques have been proposed to detect changes in LV volumes and function, including echocardiography, nuclear imaging, and MRI. The response to CRT has been assessed, usually 3-6 months after implantation, mostly using clinical or echocardiographic variables [5]. Improvement in the New York Heart Association (NYHA) functional class of at least one, increase in LVEF of $\geq 5 \%$, or reduction in LV end-systolic volume (LVESV) of $\geq 15 \%$ are the criteria used most frequently to define the response to CRT [5]. The magnitude of reverse LV remodelling, as expressed by a decrease in LVESV, has been shown to relate to the clinical outcome of heart failure patients treated with CRT [39]. Additionally, CRT may reduce functional mitral regurgitation, an effect partially dependent on reverse LV remodelling [40]. Mitral regurgitation, caused by the distortion of the mitral apparatus in the presence of intraventricular dyssynchrony, may indeed be reduced by synchronous LV contraction. This may lead to decreased left atrial pressure and consequently to reduced LV end-diastolic pressure and volume [2].

Initially, the decrease in interventricular dyssynchrony was considered the main mechanism underlying CRT response [41]. However, studies have shown that intraventricular, and not interventricular, dyssynchrony is a strong predictor of CRT response $[18,42]$. Changes in LV dyssynchrony after CRT implantation have been studied by using various echocardiographic methods, including M-mode echocardiography, tissue velocity imaging, strain rate imaging, and 3D echocardiography [5]. Figure 6 shows an example of global longitudinal strain assessed by speckle tracking 2D echocardiography. In a previous study, an improvement in global longitudinal strain, assessed by speckle tracking 2D echocardiography, was observed in CRT recipients at mid-term follow-up both under rest and exercise conditions [43]. 


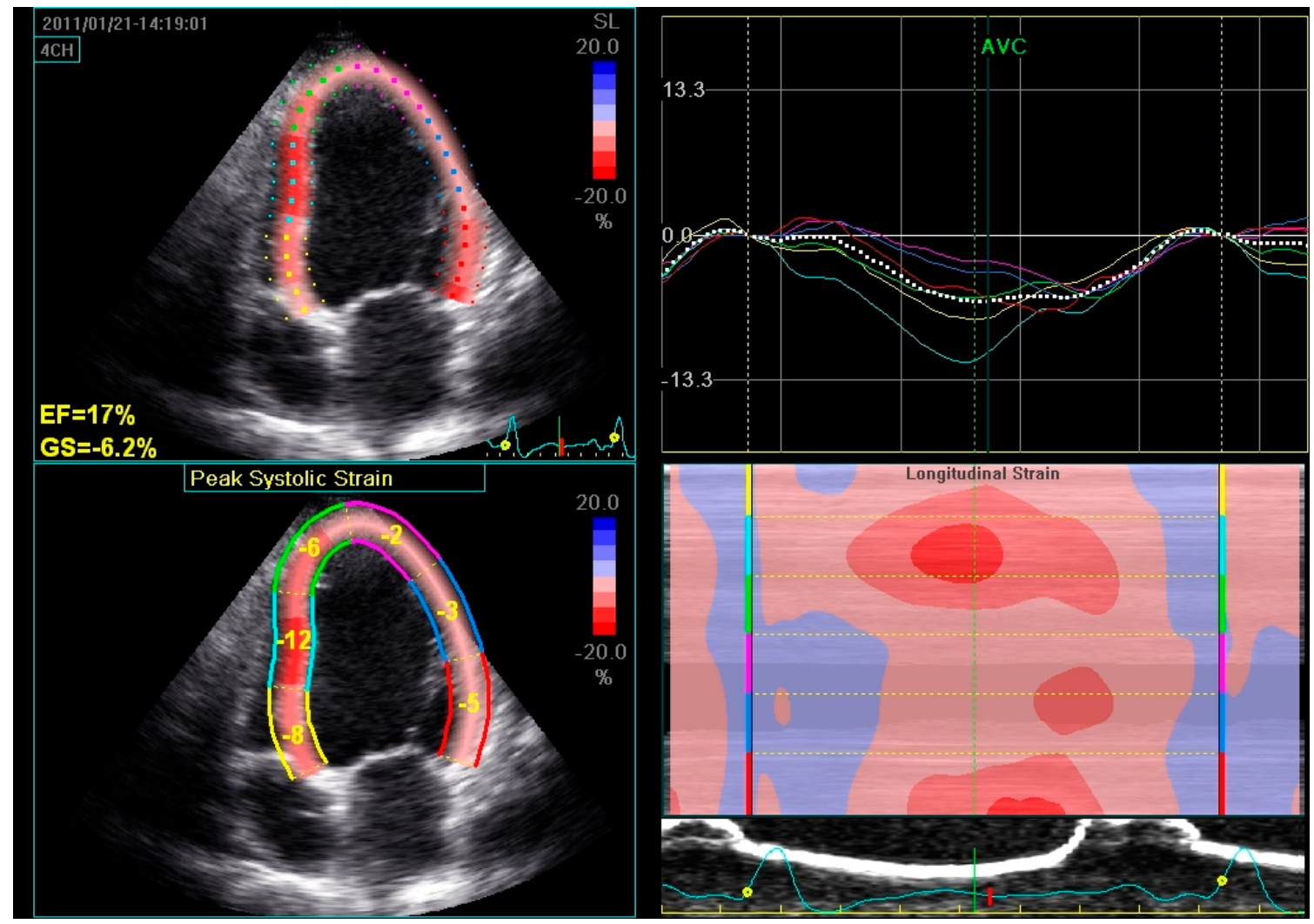

Figure 6. Global longitudinal strain assessed by speckle tracking 2D echocardiography in a patient with dilated cardiomyopathy and severe LV systolic dysfunction. The LV endocardial border is traced by the operator at end-systole and is tracked automatically during the cardiac cycle. Six LV segments, corresponding to the basal, middle, and apical regions of the septum and the lateral wall, are identified by the software. Segmental peak longitudinal strains and global longitudinal strain are assessed automatically and expressed as negative values.

Long-term changes in LV dyssynchrony have been also analysed by using nuclear imaging [44] and MRI [45]. In the study by Domenichini et al. [44], LVEF and RV ejection fraction (RVEF) were measured by radionuclide angiography at baseline and mid-term follow-up. Inter- and intraventricular dyssynchrony were assessed by Fourier phase analysis. The response to CRT was defined by an increase in LVEF of $\geq 5 \%$ at mid-term follow-up. The authors found that baseline left bundle branch block morphology was a marker of positive response to CRT in terms of improvement not only in LVEF but also in RVEF [44]. In a recent study by Vago et al. [45], CMR was performed in CRT patients at baseline and at a 6-month follow-up, with acquisitions both during biventricular pacing and right atrial pacing. Beyond conventional CMR parameters, remodelling indices, global strain, global dyssynchrony (i.e., mechanical dispersion, defined as the standard deviation of time to peak longitudinal/circumferential strain in $16 \mathrm{LV}$ segments), and regional dyssynchrony (maximum differences in time between peak septal and lateral transversal displacement), were analysed. The authors found a significant improvement in LV functional and dyssynchrony parameters during biventricular pacing at follow-up [45]. By switching from biventricular to right atrial pacing, an immediate deterioration of LV function and mechanics was observed [45].

It should be noted that, although available studies on intraventricular dyssynchrony assessment by various cardiovascular imaging techniques have given promising results in CRT patient evaluation before implantation and at follow-up, up to now no large prospective trial has proved the clinical utility of any of these dyssynchrony indexes in routine practice. Moreover, the methodology to assess the proposed dyssynchrony indexes has not been standardized yet. 
At follow-up, around 30\% of patients do not show a clinical and/or echocardiographic improvement after CRT [5]. Suboptimal patient selection and/or LV lead placement, low percentage of biventricular pacing, wide extent of myocardial scar, and non-optimized CRT programming have been suggested as factors potentially responsible for a lack of response to CRT [5]. In the sub-analysis of data from PROSPECT, van Bommel et al. [46] proposed different echocardiographic response subgroups according to the extent of LV reverse remodelling at 6-month follow-up. The suggested subgroups were: (i) super-responders (patients with a decrease in LVESV $\geq 30 \%$ ); (ii) responders (patients with a decrease in LVESV of 15-29\%); (iii) non-responders (patients with a decrease in LVESV of 0-14\%); (iv) negative responders (patients with an increase in LVESV at 6-month follow-up). In the same study [46], female gender, non-ischaemic aetiology, wide QRS duration, and no history of ventricular tachycardia were associated with greater reduction in LVESV at follow-up. NYHA class IV patients showed a poor response to CRT [46]. Both interventricular mechanical delay (defined by echo as the difference between LV and RV pre-ejection intervals) and septal-to-lateral delay (defined by echo as the delay between time to peak systolic velocity of basal septum and basal lateral wall) were strongly associated with a larger reduction in LVESV at follow-up [46]. Despite a growing body of literature, understanding non-responders to CRT is still a debated issue, and available studies suggest that the interplay of various clinical and eletromechanical variables may be responsible for the lack of response to CRT.

\subsection{CRT Optimization}

A further application of cardiovascular imaging techniques after CRT implantation is represented by CRT optimization. Patients undergoing CRT display different heart failure aetiologies and electromechanical activation patterns. CRT devices permit the programming of both the atrioventricular (AV) and the interventricular (VV) delay, thus allowing for an individually tailored activation sequence [47].

Several techniques have been proposed for CRT optimization, but echocardiography is the most widely adopted method at present. The aim of AV delay optimization is to improve LV diastolic filling, which will in turn increase LV ejection. AV delay optimization is usually performed by using Doppler-derived mitral inflow methods, in order to maximize the separation of the peak mitral $\mathrm{E}$ and A waves without A wave truncation [48]. Alternatively, AV delay can be optimized by using aortic flow methods, based on measurements of the systolic aortic velocity time integral (VTI) by either pulsed Doppler in the LV outflow tract or continuous Doppler in the aortic valve [48]. According to this approach, aortic VTI is measured at different AV delays, and the optimal AV is chosen based on the highest VTI [48]. The aim of VV delay optimization is to enhance interventricular dynamics and systolic performance. VV delay optimization can be performed by using Doppler measurements of aortic VTI or dyssynchrony indexes, derived by Tissue Doppler imaging or 3D echocardiography [49]. Optimal VV delay is chosen according to the highest aortic VTI or lowest dyssynchrony index [49].

Beyond echocardiography, CRT device optimization has been performed by using radionuclide ventriculography, with considerable variations in LVEF by changing VV delay [50]. Alternative techniques include surface electrocardiography, digital plethysmography, impedance cardiography, and automated device algorithms [47]. In a recent multicentre randomized controlled crossover trial, $\mathrm{AV}$ and VV delay optimization by using non-invasive blood pressure measurement was found to be not inferior to echocardiographic optimization, with the advantages of being less time-consuming and more easily implemented in clinical practice [51].

Available data have shown the acute beneficial effects of AV and VV delay optimization, represented by an improvement in LV filling, dyssynchrony, and systolic performance [49]. However, few studies have investigated the effects of CRT optimization at long-term follow-up. In the Insync III study [52], the optimization of CRT sequential pacing increased stroke volume but did not improve NYHA functional class and quality of life at 6-month follow-up. In the DECREASE-HF trial [53], optimized CRT did not show significant advantages over simultaneous biventricular pacing in terms of LV remodelling and systolic function at 6-month follow-up. 
In conclusion, current techniques for CRT optimization are time-consuming and lack a standard protocol. Moreover, the impact of CRT optimization on clinical outcome measures at long-term follow-up is uncertain. Therefore, CRT optimization is not widely implemented in daily clinical practice, and its use may perhaps be restricted to nonresponders, in the attempt to improve the effect of CRT [54]. Bertini et al. proposed a practical algorithm to decide when to repeat AV and VV delay optimization during follow-up [54]. According to the proposed algorithm, AV and VV delay optimization may be considered at 3-month follow-up in the event of a lack of improvement in the NYHA functional class, and at 6-month follow-up if a reduction in LVESV of $\leq 15 \%$ is observed [54].

\section{Conclusions}

Cardiovascular imaging techniques, including echocardiography, nuclear cardiology, and CMR, may be used before CRT implantation to better characterize CRT candidates in terms of LV function, dyssynchrony, and myocardial viability. Cardiac tomography may be used pre-procedurally to assess cardiac venous anatomy. Intraoperative transthoracic and intracardiac echocardiographic imaging to guide lead positioning during CRT implantation was shown to be feasible and useful in pilot studies. After implantation, various imaging techniques were used to assess CRT response and to guide the optimization of CRT programming. However, echocardiograhic dyssynchrony parameters have shown low feasibility and high interlaboratory variability. Moreover, cardiovascular imaging methodologies have often been investigated in small population studies and have not yet been standardized. Further prospective studies are, therefore, required to establish the role of functional and dyssynchrony imaging parameters in clinical decision-making and their impact on CRT patient outcome.

Author Contributions: Conceptualization, C.V. and M.J.E.; writing-original draft preparation, C.V.; writingreview and editing, M.J.E. and F.G.; visualization, E.M. and M.J.E. All authors have read and agreed to the published version of the manuscript.

Funding: This research received no external funding.

Conflicts of Interest: The authors declare no conflict of interest.

\section{References}

1. Ponikowski, P.; Voors, A.A.; Anker, S.D.; Bueno, H.; Cleland, J.G.F.; Coats, A.J.S.; Falk, V.; González-Juanatey, J.R.; Harjola, V.P.; Jankowska, E.A.; et al. 2016 ESC Guidelines for the diagnosis and treatment of acute and chronic heart failure: The Task Force for the diagnosis and treatment of acute and chronic heart failure of the European Society of Cardiology (ESC) Developed with the special contribution of the Heart Failure Association (HFA) of the ESC. Eur. Heart J. 2016, 37, 2129-2200. [PubMed]

2. Bristow, M.R.; Saxon, L.A.; Boehmer, J.; Krueger, S.; Kass, D.A.; De Marco, T.; Carson, P.; DiCarlo, L.; DeMets, D.; White, B.G.; et al. Comparison of Medical Therapy, Pacing, and Defibrillation in Heart Failure (COMPANION) Investigators. Cardiac-resynchronization therapy with or without an implantable defibrillator in advanced chronic heart failure. N. Engl. J. Med. 2004, 350, 2140-2150. [CrossRef] [PubMed]

3. Cleland, J.G.; Daubert, J.C.; Erdmann, E.; Freemantle, N.; Gras, D.; Kappenberger, L.; Tavazzi, L.; Cardiac Resynchronization-Heart Failure (CARE-HF) Study Investigators. The effect of cardiac resynchronization on morbidity and mortality in heart failure. N. Engl. J. Med. 2005, 352, 1539-1549. [CrossRef] [PubMed]

4. Moss, A.J.; Hall, W.J.; Cannom, D.S.; Klein, H.; Brown, M.W.; Daubert, J.P.; Estes, N.A., 3rd; Foster, E.; Greenberg, H.; Higgins, S.L.; et al. Cardiac-resynchronization therapy for the prevention of heart-failure events. N. Engl. J. Med. 2009, 361, 1329-1338. [CrossRef] [PubMed]

5. Bax, J.J.; Abraham, T.; Barold, S.S.; Breithardt, O.A.; Fung, J.W.; Garrigue, S.; Gorcsan, J., 3rd; Hayes, D.L.; Kass, D.A.; Knuuti, J.; et al. Cardiac resynchronization therapy: Part 1-Issues before device implantation. J. Am. Coll. Cardiol. 2005, 46, 2153-2167. [CrossRef]

6. Yu, C.M.; Chau, E.; Sanderson, J.E.; Fan, K.; Tang, M.O.; Fung, W.H.; Lin, H.; Kong, S.L.; Lam, Y.M.; Hill, M.R.; et al. Tissue Doppler echocardiographic evidence of reverse remodeling and improved synchronicity by simultaneously delaying regional contraction after biventricular pacing therapy in heart failure. Circulation 2002, 105, 438-445. [CrossRef] 
7. Linde, C.; Ellenbogen, K.; McAlister, F.A. Cardiac resynchronization therapy (CRT): Clinical trials, guidelines, and target populations. Heart Rhythm. 2012, 9 (Suppl. 8), S3-S13. [CrossRef]

8. Chung, E.S.; Leon, A.R.; Tavazzi, L.; Sun, J.P.; Nihoyannopoulos, P.; Merlino, J.; Abraham, W.T.; Ghio, S.; Leclercq, C.; Bax, J.J.; et al. Results of the Predictors of Response to CRT (PROSPECT) trial. Circulation 2008, 117, 2608-2616. [CrossRef]

9. D'Andrea, A.; Caso, P.; Scarafile, R.; Riegler, L.; Salerno, G.; Castaldo, F.; Gravino, R.; Cocchia, R.; Del Viscovo, L.; Limongelli, G.; et al. Effects of global longitudinal strain and total scar burden on response to cardiac resynchronization therapy in patients with ischaemic dilated cardiomyopathy. Eur. J. Heart Fail. 2009, 11, 58-67. [CrossRef]

10. Delgado, V.; Ypenburg, C.; van Bommel, R.J.; Tops, L.F.; Mollema, S.A.; Marsan, N.A.; Bleeker, G.B.; Schalij, M.J.; Bax, J.J. Assessment of left ventricular dyssynchrony by speckle tracking strain imaging comparison between longitudinal, circumferential, and radial strain in cardiac resynchronization therapy. J. Am. Coll. Cardiol. 2008, 51, 1944-1952. [CrossRef]

11. Höke, U.; Bax, J.J.; Delgado, V.; Ajmone Marsan, N. Assessment of left ventricular dyssynchrony by three-dimensional echocardiography: Prognostic value in patients undergoing cardiac resynchronization therapy. J. Cardiovasc. Electrophysiol. 2018, 29, 780-787. [CrossRef] [PubMed]

12. Sassone, B.; Nucifora, G.; Mele, D.; Valzania, C.; Boriani, G.; for Task Force on Imaging of Italian Association of Arrhythmias and Cardiac Stimulation (AIAC). Role of cardiovascular imaging in cardiac resynchronization therapy: A literature review. J. Cardiovasc. Med. Hagerstown 2018, 19, 211-222. [CrossRef] [PubMed]

13. Stankovic, I.; Prinz, C.; Ciarka, A.; Daraban, A.M.; Kotrc, M.; Aarones, M.; Szulik, M.; Winter, S.; Belmans, A.; Neskovic, A.N.; et al. Relationship of visually assessed apical rocking and septal flash to response and long-term survival following cardiac resynchronization therapy (PREDICT-CRT). Eur. Heart J. Cardiovasc. Imaging 2016, 17, 262-269. [CrossRef] [PubMed]

14. Salden, O.A.E.; Zweerink, A.; Wouters, P.; Allaart, C.P.; Geelhoed, B.; de Lange, F.J.; Maass, A.H.; Rienstra, M.; Vernooy, K.; Vos, M.A.; et al. The value of septal rebound stretch analysis for the prediction of volumetric response to cardiac resynchronization therapy. Eur. Heart J. Cardiovasc. Imaging 2020, in press. [CrossRef]

15. Borgquist, R.; Carlsson, M.; Markstad, H.; Werther-Evaldsson, A.; Ostenfeld, E.; Roijer, A.; Bakos, Z. Cardiac Resynchronization Therapy Guided by Echocardiography, MRI, and CT Imaging: A Randomized Controlled Study. JACC Clin. Electrophysiol. 2020, 6, 1300-1309. [CrossRef]

16. Gorcsan, J., 3rd; Abraham, T.; Agler, D.A.; Bax, J.J.; Derumeaux, G.; Grimm, R.A.; Martin, R.; Steinberg, J.S.; Sutton, M.S.; Yu, C.M.; et al. Echocardiography for cardiac resynchronization therapy: Recommendations for performance and reporting-A report from the American Society of Echocardiography Dyssynchrony Writing Group endorsed by the Heart Rhythm Society. J. Am. Soc. Echocardiogr. 2008, 21, 191-213. [CrossRef]

17. Valzania, C.; Bonfiglioli, R.; Fallani, F.; Martignani, C.; Ziacchi, M.; Diemberger, I.; Biffi, M.; Fanti, S.; Galiè, N. Single-photon cardiac imaging in patients with cardiac implantable electrical devices. J. Nucl. Cardiol. 2020, in press. [CrossRef]

18. Fauchier, L.; Marie, O.; Casset-Senon, D.; Babuty, D.; Cosnay, P.; Fauchier, J.P. Interventricular and intraventricular dyssynchrony in idiopathic dilated cardiomyopathy: A prognostic study with fourier phase analysis of radionuclide angioscintigraphy. J. Am. Coll. Cardiol. 2002, 40, 2022-2030. [CrossRef]

19. Valzania, C.; Biffi, M.; Bonfiglioli, R.; Fallani, F.; Martignani, C.; Diemberger, I.; Ziacchi, M.; Frisoni, J.; Tomasi, L.; Fanti, S.; et al. Effects of cardiac resynchronization therapy on right ventricular function during rest and exercise, as assessed by radionuclide angiography, and on NT-proBNP levels. J. Nucl. Cardiol. 2019, 26, 123-132. [CrossRef]

20. Badhwar, N.; James, J.; Hoffmayer, K.S.; O'Connell, J.W.; Green, D.; De Marco, T.; Botvinick, E.H. Utility of Equilibrium Radionuclide Angiogram-Derived Measures of Dyssynchrony to Predict Outcomes in Heart Failure Patients Undergoing Cardiac Resynchronization Therapy. J. Nucl. Med. 2016, 57, 1880-1886. [CrossRef]

21. Juarez-Orozco, L.E.; Monroy-Gonzalez, A.; Prakken, N.H.J.; Noordzij, W.; Knuuti, J.; deKemp, R.A.; Slart, R.H.J.A. Phase analysis of gated PET in the evaluation of mechanical ventricular synchrony: A narrative overview. J. Nucl. Cardiol. 2019, 26, 1904-1913. [CrossRef] [PubMed] 
22. Chalil, S.; Stegemann, B.; Muhyaldeen, S.; Khadjooi, K.; Smith, R.E.; Jordan, P.J.; Leyva, F. Intraventricular dyssynchrony predicts mortality and morbidity after cardiac resynchronization therapy: A study using cardiovascular magnetic resonance tissue synchronization imaging. J. Am. Coll. Cardiol. 2007, 50, 243-252. [CrossRef] [PubMed]

23. Bilchick, K.C.; Dimaano, V.; Wu, K.C.; Helm, R.H.; Weiss, R.G.; Lima, J.A.; Berger, R.D.; Tomaselli, G.F.; Bluemke, D.A.; Halperin, H.R.; et al. Cardiac magnetic resonance assessment of dyssynchrony and myocardial scar predicts function class improvement following cardiac resynchronization therapy. JACC Cardiovasc. Imaging 2008, 1, 561-568. [CrossRef] [PubMed]

24. Aalen, J.M.; Donal, E.; Larsen, C.K.; Duchenne, J.; Lederlin, M.; Cvijic, M.; Hubert, A.; Voros, G.; Leclercq, C.; Bogaert, J.; et al. Imaging predictors of response to cardiac resynchronization therapy: Left ventricular work asymmetry by echocardiography and septal viability by cardiac magnetic resonance. Eur. Heart J. 2020, in press. [CrossRef] [PubMed]

25. Kloosterman, M.; Damman, K.; Van Veldhuisen, D.J.; Rienstra, M.; Maass, A.H. The importance of myocardial contractile reserve in predicting response to cardiac resynchronization therapy. Eur. J. Heart Fail. 2017, 19, 862-869. [CrossRef] [PubMed]

26. Ciampi, Q.; Carpeggiani, C.; Michelassi, C.; Villari, B.; Picano, E. Left ventricular contractile reserve by stress echocardiography as a predictor of response to cardiac resynchronization therapy in heart failure: A systematic review and meta-analysis. BMC Cardiovasc. Disord. 2017, 17, 223. [CrossRef]

27. Adelstein, E.C.; Saba, S. Scar burden by myocardial perfusion imaging predicts echocardiographic response to cardiac resynchronization therapy in ischemic cardiomyopathy. Am. Heart J. 2007, 153, 105-112. [CrossRef]

28. Bose, A.; Kandala, J.; Upadhyay, G.A.; Riedl, L.; Ahmado, I.; Padmanabhan, R.; Gewirtz, H.; Mulligan, L.J.; Singh, J.P. Impact of myocardial viability and left ventricular lead location on clinical outcome in cardiac resynchronization therapy recipients with ischemic cardiomyopathy. J. Cardiovasc. Electrophysiol. 2014, 25, 507-513. [CrossRef]

29. Lehner, S.; Uebleis, C.; Schüßler, F.; Haug, A.; Kääb, S.; Bartenstein, P.; Van Kriekinge, S.D.; Germano, G.; Estner, H.; Hacker, M. The amount of viable and dyssynchronous myocardium is associated with response to cardiac resynchronization therapy: Initial clinical results using multiparametric ECG-gated [18F]FDG PET. Eur. J. Nucl. Med. Mol. Imaging 2013, 40, 1876-1883. [CrossRef]

30. Leyva, F.; Foley, P.W.; Chalil, S.; Ratib, K.; Smith, R.E.; Prinzen, F.; Auricchio, A. Cardiac resynchronization therapy guided by late gadolinium-enhancement cardiovascular magnetic resonance. J. Cardiovasc. Magn. Reson. 2011, 13, 29. [CrossRef]

31. Taylor, R.J.; Umar, F.; Panting, J.R.; Stegemann, B.; Leyva, F. Left ventricular lead position, mechanical activation, and myocardial scar in relation to left ventricular reverse remodeling and clinical outcomes after cardiac resynchronization therapy: A feature-tracking and contrast-enhanced cardiovascular magnetic resonance study. Heart Rhythm. 2016, 13, 481-489. [PubMed]

32. Van de Veire, N.R.; Schuijf, J.D.; De Sutter, J.; Devos, D.; Bleeker, G.B.; de Roos, A.; van der Wall, E.E.; Schalij, M.J.; Bax, J.J. Non-invasive visualization of the cardiac venous system in coronary artery disease patients using 64-slice computed tomography. J. Am. Coll. Cardiol. 2006, 48, 1832-1838. [CrossRef] [PubMed]

33. Girsky, M.J.; Shinbane, J.S.; Ahmadi, N.; Mao, S.; Flores, F.; Budoff, M.J. Prospective randomized trial of venous cardiac computed tomographic angiography for facilitation of cardiac resynchronization therapy. Pacing Clin. Electrophysiol. 2010, 33, 1182-1187. [CrossRef] [PubMed]

34. Tada, T.; Osuda, K.; Nakata, T.; Muranaka, I.; Himeno, M.; Muratsubaki, S.; Murase, H.; Sato, K.; Hirose, M.; Fukuma, T. A novel approach to the selection of an appropriate pacing position for optimal cardiac resynchronization therapy using CT coronary venography and myocardial perfusion imaging: FIVE STaR method (fusion image using CT coronary venography and perfusion SPECT applied for cardiac resynchronization therapy). J. Nucl. Cardiol. 2019, in press.

35. Bai, R.; Di Biase, L.; Mohanty, P.; Hesselson, A.B.; De Ruvo, E.; Gallagher, P.L.; Elayi, C.S.; Mohanty, S.; Sanchez, J.E.; Burkhardt, J.D.; et al. Positioning of left ventricular pacing lead guided by intracardiac echocardiography with vector velocity imaging during cardiac resynchronization therapy procedure. J. Cardiovasc. Electrophysiol. 2011, 22, 1034-1041. [CrossRef]

36. Moubarak, G.; Ritter, P.; Daubert, J.C.; Cazeau, S. First experience of intraoperative echocardiography-guided optimization of cardiac resynchronization therapy delivery. Arch. Cardiovasc. Dis. 2014, 107, 169-177. [CrossRef] 
37. Sperzel, J.; Brandt, R.; Hou, W.; Doelger, A.; Zdarek, J.; Rosenberg, S.P.; Ryu, K.; Koh, S.; Yang, M. Intraoperative characterization of interventricular mechanical dyssynchrony using electroanatomic mapping system-A feasibility study. J. Interv. Card. Electrophysiol. 2012, 35, 189-196. [CrossRef]

38. Salden, O.A.E.; van den Broek, H.T.; van Everdingen, W.M.; Mohamed Hoesein, F.A.A.; Velthuis, B.K.; Doevendans, P.A.; Cramer, M.J.; Tuinenburg, A.E.; Leufkens, P.; van Slochteren, F.J.; et al. Multimodality imaging for real-time image-guided left ventricular lead placement during cardiac resynchronization therapy implantations. Int. J. Cardiovasc. Imaging 2019, 35, 1327-1337. [CrossRef]

39. Ypenburg, C.; van Bommel, R.J.; Borleffs, C.J.; Bleeker, G.B.; Boersma, E.; Schalij, M.J.; Bax, J.J. Long-term prognosis after cardiac resynchronization therapy is related to the extent of left ventricular reverse remodeling at midterm follow-up. J. Am. Coll. Cardiol. 2009, 53, 483-490. [CrossRef]

40. Ypenburg, C.; Lancellotti, P.; Tops, L.F.; Bleeker, G.B.; Holman, E.R.; Piérard, L.A.; Schalij, M.J.; Bax, J.J. Acute effects of initiation and withdrawal of cardiac resynchronization therapy on papillary muscle dyssynchrony and mitral regurgitation. J. Am. Coll. Cardiol. 2007, 50, 2071-2077. [CrossRef]

41. Ypenburg, C.; Westenberg, J.J.; Bleeker, G.B.; VAN de Veire, N.; Marsan, N.A.; Henneman, M.M.; van der Wall, E.E.; Schalij, M.J.; Abraham, T.P.; Barold, S.S.; et al. Noninvasive imaging in cardiac resynchronization therapy—Part 1: Selection of patients. Pacing Clin. Electrophysiol. 2008, 31, 1475-1499. [CrossRef] [PubMed]

42. Bax, J.J.; Bleeker, G.B.; Marwick, T.H.; Molhoek, S.G.; Boersma, E.; Steendijk, P.; van der Wall, E.E.; Schalij, M.J. Left ventricular dyssynchrony predicts response and prognosis after cardiac resynchronization therapy. J. Am. Coll. Cardiol. 2004, 44, 1834-1840. [CrossRef] [PubMed]

43. Valzania, C.; Gadler, F.; Boriani, G.; Eriksson, M.J. Changes in global longitudinal strain during rest and exercise in patients treated with cardiac resynchronization therapy. Clin. Physiol. Funct. Imaging 2012, 32, 310-316. [CrossRef] [PubMed]

44. Domenichini, G.; Burri, H.; Valzania, C.; Gavaruzzi, G.; Fallani, F.; Biffi, M.; Sunthorn, H.; Diemberger, I.; Martignani, C.; Foulkes, H.; et al. QRS pattern and improvement in right and left ventricular function after cardiac resynchronization therapy: A radionuclide study. BMC Cardiovasc. Disord. 2012, 12, 27. [CrossRef] [PubMed]

45. Vago, H.; Czimbalmos, C.; Papp, R.; Szabo, L.; Toth, A.; Dohy, Z.; Csecs, I.; Suhai, F.; Kosztin, A.; Molnar, L.; et al. Biventricular pacing during cardiac magnetic resonance imaging. Europace 2020, 22, 117-124. [CrossRef] [PubMed]

46. van Bommel, R.J.; Bax, J.J.; Abraham, W.T.; Chung, E.S.; Pires, L.A.; Tavazzi, L.; Zimetbaum, P.J.; Gerritse, B.; Kristiansen, N.; Ghio, S. Characteristics of heart failure patients associated with good and poor response to cardiac resynchronization therapy: A PROSPECT (Predictors of Response to CRT) sub-analysis. Eur. Heart J. 2009, 30, 2470-2477. [CrossRef] [PubMed]

47. Burri, H.; Sunthorn, H.; Shah, D.; Lerch, R. Optimization of device programming for cardiac resynchronization therapy. Pacing Clin. Electrophysiol. 2006, 29, 1416-1425. [CrossRef] [PubMed]

48. Waggoner, A.D.; de las Fuentes, L.; Davila-Roman, V.G. Doppler echocardiographic methods for optimization of the atrioventricular delay during cardiac resynchronization therapy. Echocardiography 2008, 25, 1047-1055. [CrossRef]

49. Bhan, A.; Kapetanakis, S.; Monaghan, M.J. Optimization of cardiac resynchronization therapy. Echocardiography 2008, 25, 1031-1039. [CrossRef]

50. Burri, H.; Sunthorn, H.; Somsen, A.; Zaza, S.; Fleury, E.; Shah, D.; Righetti, A. Optimizing sequential biventricular pacing using radionuclide ventriculography. Heart Rhythm. 2005, 2, 960-965. [CrossRef]

51. Whinnett, Z.I.; Sohaib, S.M.A.; Mason, M.; Duncan, E.; Tanner, M.; Lefroy, D.; Al-Obaidi, M.; Ellery, S.; Leyva-Leon, F.; Betts, T.; et al. Multicenter Randomized Controlled Crossover Trial Comparing Hemodynamic Optimization Against Echocardiographic Optimization of AV and VV Delay of Cardiac Resynchronization Therapy: The BRAVO Trial. JACC Cardiovasc. Imaging 2019, 12, 1407-1416. [CrossRef] [PubMed]

52. León, A.R.; Abraham, W.T.; Brozena, S.; Daubert, J.P.; Fisher, W.G.; Gurley, J.C.; Liang, C.S.; Wong, G.; InSync III Clinical Study Investigators. Cardiac resynchronization with sequential biventricular pacing for the treatment of moderate-to-severe heart failure. J. Am. Coll. Cardiol. 2005, 46, 2298-2304. [CrossRef] [PubMed]

53. Rao, R.K.; Kumar, U.N.; Schafer, J.; Viloria, E.; De Lurgio, D.; Foster, E. Reduced ventricular volumes and improved systolic function with cardiac resynchronization therapy: A randomized trial comparing simultaneous biventricular pacing, sequential biventricular pacing, and left ventricular pacing. Circulation 2007, 115, 2136-2144. [CrossRef] [PubMed] 
54. Bertini, M.; Delgado, V.; Bax, J.J.; Van de Veire, N.R. Why, how and when do we need to optimize the setting of cardiac resynchronization therapy? Europace 2009, 11 (Suppl. 5), v46-v57. [CrossRef] [PubMed]

Publisher's Note: MDPI stays neutral with regard to jurisdictional claims in published maps and institutional affiliations.

(C) 2020 by the authors. Licensee MDPI, Basel, Switzerland. This article is an open access article distributed under the terms and conditions of the Creative Commons Attribution (CC BY) license (http://creativecommons.org/licenses/by/4.0/). 